\title{
Biological Deacidification Strategies for White Wines
}

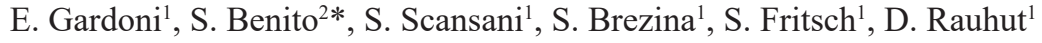 \\ (1) Department of Microbiology and Biochemistry, Hochschule Geisenheim University, Germany \\ (2) Department of Chemistry and Food Technology, Polytechnic University of Madrid, Spain
}

Submitted for publication: January 2021

Accepted for publication: May 2021

Key words: Schizosaccharomyces pombe, Lachancea thermotolerans, Lactiplantibacillus plantarum, Oenococcus oeni, wine, malic acid

\begin{abstract}
Traditionally, the use of malolactic fermentation gives rise to microbiologically stable wines. However, malolactic fermentation is not free from possible collateral effects that can take place under specific scenarios. The present work tests the influence of different biological deacidification strategies on the volatile and non-volatile components of white must from Germany. The study compared mixed cultures of Lachancea thermotolerans and Schizosaccharomyces pombe and a pure culture of Sc. pombe to the classical biological deacidification process performed by lactic acid bacteria. Strains of Oenococcus oeni and Lactiplantibacillus plantarum were co- or sequentially inoculated with $S$. cerevisiae to carry out malolactic fermentation. Different fermentation treatments took place at a laboratory scale of $0.6 \mathrm{~L}$ in vessels of $0.75 \mathrm{~L}$. The instrumental techniques Fourier-transform mid-infrared spectroscopy (FT-MIR), high performance liquid chromatography (HPLC) and gas chromatography-mass spectrometry (GC-MS) were used to evaluate different chemical parameters in the final wines. The results showed the ability of $S c$. pombe to consume malic acid in combination with $L$. thermotolerans without using $S$. cerevisiae or lactic acid bacteria. Fermentations involving $S c$. pombe consumed all the malic acid, although they reduced the concentrations of higher alcohols, fatty acids and acetic acid. Simultaneous alcoholic and malolactic fermentations reduced malic acid by about $80 \%$, while classical malolactic fermentation reduced it by $\mathbf{1 0 0} \%$. Fermentations involving $L$. thermotolerans produced the highest lactic acid, ester and glycerol concentrations.
\end{abstract}

\section{INTRODUCTION}

The classical winemaking process may include two main microbiological steps. The first one is alcoholic fermentation, which is carried out mostly by $S$. cerevisiae, but sometimes by other yeast species. The second one is malolactic fermentation (MLF), which usually is induced by lactic acid bacteria (LAB), such as Oenococcus oeni (Knoll et al., 2011, 2012; Sumby et al., 2014; Bartowsky et al., 2015; Du Plessis et al., 2017a) and Lactiplantibacillus plantarum (formerly Lactobacillus plantarum) (Du Toit et al., 2011; Iorizzo et al., 2016; Lucio et al., 2016, 2018; Brizuela et al., 2018; Du Plessis et al., 2019; Olguin et al., 2020). Traditionally, MLF is used to obtain microbiologically stable wines - both red wines and some white wines, and especially those that undergo barrel or bottle ageing (Bartowsky et al., 2015; Sumby et al., 2019). However, MLF may present some collateral effects in specific situations, such as offflavour development and the production of potentially toxic products, i.e. biogenic amines (Smit \& Du Toit, 2013) and ethyl carbamate (Benito et al., 2015a; Sumby et al., 2019).
Depending on the initial $\mathrm{pH}$, the removal of L-malic acid can be detrimental to wine, especially wines coming from warm regions that may show high $\mathrm{pH}$ and low acidity (Volschenk et al., 2006; Dicks \& Endo, 2009; Benito et al., 2016a). This scenario has opened the doors for the study of new biological deacidification strategies with specific nonSaccharomyces yeasts (Vilela, 2019; Benito, 2019). The Schizosaccharomyces genus shows the highest efficiency in wine deacidification. Schizosaccharomyces spp. can degrade malic acid (Jolly et al., 2014; Domizio et al., 2017, 2018; Minnaar et al., 2017a) via malo-ethanolic fermentation, leading to the production of ethanol and carbon dioxide (Benito, 2019).

Due to an increasingly sophisticated and fragmented market, consumers request different wine styles with healthier and more sustainable appeal. In addition, because of the change in wine composition due to the increase in the average global temperature, some strains, such as Sc. pombe and Lachancea thermotolerans, are receiving particular

\footnotetext{
*Corresponding author: santiago.benito@upm.es [Tel.: +34-91-3363710]

Acknowledgements: We thank Mrs Anja Giehl (Department of Beverage Research, HGU), for her assistance in the FTIR measurements, Mrs Carmen Dost, for her support in controlling the fermentation trial, and Mrs Heike Semmler, for her help with the HPLC analysis (Department of Microbiology and Biochemistry, HGU). Funding for Santiago Benito was provided by the Spanish Center for the Development of Industrial Technology under the framework of Project IDI20210391 and for the Ministry of Science and Innovation under the framework of Project PID2020-119008RB-I00
} 
attention (Jolly et al., 2014; Roudil et al., 2019; Benito, 2020).

The aim of this study was to compare the different available biological deacidification strategies and their influence on white wine production.

\section{MATERIALS AND METHODS \\ Microorganisms}

The following yeast and bacterial strains were used for the experimental fermentations of the white grape musts: Saccharomyces cerevisiae Lalvin QA23 ${ }^{\circledR}$ (Lallemand, Montreal, Canada), Schizosaccharomyces pombe V2 (Benito et al., 2014a, 2016b; Scansani et al., 2020), Lachancea thermotolerans Concerto ${ }^{\mathrm{TM}}$ (Hansen, Hoersholm, Denmark), Oenococcus oeni (commercial strain) and Lactiplantibacillus plantarum (commercial strain). Due to a confidentiality agreement with the supplier, the names of the lactic acid bacteria may not be mentioned. The authors can be contacted if anyone needs further information.

\section{Vinification process}

The microvinifications were performed according to a previously described methodology (Dutraive et al., 2019), which was adapted to $0.75 \mathrm{~L}$ fermentation vessels. Must of the Riesling grape variety (Hochschule Geisenheim University, Germany) was used for all the fermentations. Constituent concentrations in the initial must were as follows: total sugar, $201.7 \mathrm{~g} / \mathrm{L}$; tartaric acid, $5.0 \mathrm{~g} / \mathrm{L}$; malic acid, $4.7 \mathrm{~g} / \mathrm{L}$; total acidity, $10.48 \mathrm{~g} / \mathrm{L}$; lactic and acetic acid, $<0.1 \mathrm{~g} / \mathrm{L} ; \mathrm{pH}$, 3.09; yeast-assimilable nitrogen content (YAN), $140 \mathrm{mg} / \mathrm{L}$.

OptiMUM WHITEтм $(0.4 \mathrm{~g} / \mathrm{L}$, Lallemand, Montreal, Canada) and FERMAID ETM $(0.4 \mathrm{~g} / \mathrm{L}$, Lallemand $)$ were added to the must to provide nutrition to the microorganisms. No sulphur dioxide was added, as the initial must was previously sterilised by fine filtration $(0.22 \mu \mathrm{m})$, subsequently saturated with carbon dioxide gas and stored at a pressure of $600 \mathrm{kPa}$ and a temperature of $0^{\circ} \mathrm{C}$ (Kanter et al., 2020). Then, $0.6 \mathrm{~L}$ of must were placed in $0.75 \mathrm{~L}$ sterilised glass fermentation vessels sealed with a fermentation airlock. The fermentation airlocks were filled with an aqueous solution of $20 \mathrm{~g} / \mathrm{L}$ of potassium metabisulfite (Merck, Darmstadt, Germany), which allowed for the release of $\mathrm{CO}_{2}$ while avoiding microbial contamination. Six treatments were performed in triplicate: (i) pure culture of $S$. cerevisiae $(S C)$; (ii) $S$. cerevisiae followed by $O$. oeni at the end of alcoholic fermentation (SC...OE); (iii) $S$. cerevisiae followed by $O$. oeni after five hours ( $S C x O E)$; (iv) $S$. cerevisiae followed by L. plantarum after five hours (SCxLB); (v) L. thermotolerans followed by Sc. pombe after 96 hours (LT...SP); and (vi) pure culture of $S c$. pombe $(S P)$. All the strains were inoculated under aseptic conditions. The yeast and bacteria were inoculated at a population of $10^{6} \mathrm{cfu} / \mathrm{mL}$. The inoculums were prepared by rehydrating $100 \mathrm{mg}$ of the corresponding commercial strain product in $10 \mathrm{~mL}$ of sterilised water under sterile laboratory conditions. The number of cells was evaluated by cell counting using a Thoma counting chamber, Blaubrand ${ }^{\circledR}$ (Brand, Wertheim, Germany), in a Leica DM 500 microscope (Wetzlar, Germany). The sequential MLF treatment, with $S$. cerevisiae followed by $O$. oen $i$ after alcoholic fermentation $(S C \ldots O E)$, was inoculated with $O$. oeni at $10^{7} \mathrm{cfu} / \mathrm{mL}$. MLF was performed in $0.5 \mathrm{~L}$ vessels at $18^{\circ} \mathrm{C}$ until malic acid was totally degraded. Only the sequential fermentation $(S C \ldots$ $O E$ ) performed $\mathrm{MLF}$ at $18^{\circ} \mathrm{C}$ after alcoholic fermentation by $S$. cerevisiae. The other alcoholic fermentations and simultaneous MLF $(S C x O E ; S C x L P)$ treatments were performed at $20^{\circ} \mathrm{C}$. Once the weight loss remained constant for 48 hours, the wines were racked and stabilised for 15 days at $4^{\circ} \mathrm{C}$, and the final product was bottled in $125 \mathrm{~mL}$ bottles. Potassium metabisulfite (Merck, Darmstadt, Germany) was added to achieve a concentration of $80 \mathrm{mg} / \mathrm{L}$ total sulphur dioxide. The bottles were sealed with aluminium screw caps and were placed in a climate chamber at $4{ }^{\circ} \mathrm{C}$ until the chemical analyses were performed.

\section{Analytical determination of non-volatile compounds}

The determination of total acidity, residual sugar, density, ethanol, glycerol, extract, sugar-free extract and the $\mathrm{pH}$ of the must and wine was carried out with the standard operating procedure SOP-WG1-84 of the Department of Beverage Research of Hochschule Geisenheim University (HGU; Germany) based on Fourier-transform mid-infrared spectroscopy (FT-MIR) (Patz et al., 2004; Friedel et al., 2013; Kanter et al., 2020). The determination of L-malic acid, L-lactic acid and acetic acid was performed by HPLC (Kanter et al., 2020). For this purpose, we used the 1100 Series system of Agilent Technologies (Santa Clara, USA), equipped with an Allure Organic Acids ${ }^{\mathrm{TM}}$ column (Restek GmbH, Germany) (250 mm x 4.6 mm I.D. x $5 \mu \mathrm{m}$ grain size $\mathrm{x}$ $60 \AA \AA$ pore size), preceded by a $4 \mathrm{~mm}$ x $3.0 \mathrm{~mm}$ inner diameter precolumn (Security Guard C18 ${ }^{\mathrm{TM}}$, Phenomenex, Germany). Analytes were detected by a refractive index detector (RID) and a multiwavelength detector (MWD). The samples were analysed in scan mode. $\mathrm{pH}$ values were measured using a pH electrode (WTW pH meter pH 526) (Xylem Analytics Germany Sales GmbH \& Co. KG, Weilheim, Germany).

\section{Analytical determination of YAN}

YAN levels in the must were measured using the NOPA technique (nitrogen by derivatisation with orthophthaldialdehyde (OPA)), following the directions of Dukes and Butzke (2013). NOPA determination was carried out using the Thermo Scientific ${ }^{\text {TM }}$ Evolution 220 UV-visible Spectrophotometer (Fisher Scientific, New Hampshire, USA).

\section{Analytical determination of volatile compounds}

The determination of ester, higher alcohol and fatty acid concentrations was carried out at Hochschule Geisenheim University (Germany) by the Department of Microbiology and Biochemistry according to Rapp et al. (1994) with modifications (Kanter et al., 2020; Scansani et al., 2020). A gas chromatograph GC 5890 Series II (Hewlett-Packard, Palo Alto, USA) was used. For the sample preparation, $2 \mathrm{~g}$ of $\mathrm{NaCl}$ (Carl Roth, Karlsruhe, Germany) was weighed into a $15 \mathrm{~mL}$ sample vessel and $10 \mathrm{~mL}$ of wine was added. Then, $10 \mu \mathrm{L}$ of the internal standard, 2,6-dimethyl-5-hepten2-ol (DMH) (stock concentration $1219 \mu \mathrm{g} / \mathrm{L}$ ) (Carl Roth, Karlsruhe, Germany), was added for the quantification, $10 \mu \mathrm{L}$ of the internal standard Cumol (Honeywell, Morris Plains, USA) (stock concentration $170 \mu \mathrm{g} / \mathrm{L}$ ) was added for the 
control, and $160 \mu \mathrm{L}$ of 1,1,2-trichlorotrifluoroethane (Merck, Darmstadt, Germany) was added as extracting agent. The mixture was agitated for $20 \mathrm{~min}$ and centrifuged for $8 \mathrm{~min}$ (3 $000 \mathrm{rpm} ; 1700 \mathrm{~g}$ ). The extract was removed with a glass pipette and transferred to a sample vial for analysis. The cold injection system, KAS 3 (Gerstel, Mülheim an der Ruhr, Germany), was used for sample injection. Two microlitres of the sample were injected in splitless mode (starting temperature $40^{\circ} \mathrm{C}$; heating rate $3^{\circ} \mathrm{C} / \mathrm{min}$ to $125^{\circ} \mathrm{C}$; holding time $4 \mathrm{~min}$ and $6^{\circ} \mathrm{C} / \mathrm{min}$ to $200^{\circ} \mathrm{C}$; holding time $14.2 \mathrm{~min}$ ). The instrument was fitted with the Varian VF-5 MS column from Agilent (Santa Clara, USA) with dimensions of $60 \mathrm{~m}$ x $320 \mu \mathrm{m}$ x $1 \mu \mathrm{m}$. Helium (Linde Gas, Bingen, Germany) was used as the carrier gas at a flow rate of $1 \mathrm{~mL} / \mathrm{min}$. The detection was performed by mass spectrometry (5972 MSD, Hewlett-Packard) in scan mode, covering a mass-to-charge ratio from 35 to 250 . The voltage of electron impact was set at $70 \mathrm{mV}$.

\section{Statistical analysis}

For the statistical evaluation of the data, the means and standard deviations of the wine sample triplicates were calculated. One-way ANOVA and multiple range tests were performed using Statgraphics Centurion V17.2.05 software (Graphics Software Systems, Rockville, MD, USA). The significance level was set at $\mathrm{p}<0.05$. A multiple range test was used to compare and group the mean values of the variants according to the Fisher's least significant difference (LSD) method. These are identified by the letters a to $\mathrm{d}$ in the tables.

\section{RESULTS AND DISCUSSION \\ Non-volatile compounds \\ Ethanol production}

The final ethanol levels varied from $11.75 \%$ to $12.21 \%(\mathrm{v} / \mathrm{v})$. The final density, together with the residual sugar values, showed that all the treatments reached dryness (Table 1). Alcoholic fermentations involving Sc. pombe fermented slower than the fermentations involving $S$. cerevisiae (Fig. 1). The Sc. pombe fermentation produced the highest final concentration of ethanol, while the other fermentations did not show significant statistical differences. This effect took place because the conversion of malic acid into ethanol is clearer for $S c$. pombe when the initial content of malic acid is high (Minnaar et al., 2017a). LT...SP produced the lowest concentration of ethanol (Table 1). Fermentations involving $L$. thermotolerans consistently contained lower ethanol concentrations, even in sequential inoculations with S. cerevisiae (Gobbi et al., 2013). In the present study, $L$. thermotolerans proved to be a suitable tool to mitigate the higher ethanol production obtained from Sc. pombe fermentation. Yeast may use sugars as a source for the synthesis of molecules other than ethanol, including glycerol, pyruvic acid and lactic acid, or to increase yeast biomass (Benito et al., 2015a; Benito, 2018; Hranilovic et al., 2018).

\section{Glycerol}

Glycerol is one of the major yeast metabolites synthesised during fermentation and is the third most important metabolite after ethanol and $\mathrm{CO}_{2}$. It may contribute to the smoothness, sweetness and complexity of wine (Jolly et al., 2014). In this study, the final concentrations of glycerol varied from 5.9 to $7.3 \mathrm{~g} / \mathrm{L}$ (Table 1 ). Treatments involving $S$. cerevisiae did not differ significantly from each other (Table 1), while sequential fermentation with $L$. thermotolerans and $S$. pombe $(L T \ldots S P)$ showed the highest final glycerol content. This agrees with previous studies that reported $L$. thermotolerans as a high glycerol producer (Comitini et al., 2011; Gobbi et al., 2013; Benito, 2018; Porter et al., 2019b). Using L. thermotolerans in mixed fermentation with $S$. cerevisiae positively increases glycerol production (Gobbi et al., 2013). The selected $S$. cerevisiae and $L$. thermotolerans strains might have had better-developed glycerol-pyruvic pathways than the selected $S c$. pombe strain, as they generated lower final concentrations of ethanol and higher concentrations of glycerol (Table 1). Although some studies report Sc. pombe to synthesise higher amounts of glycerol than some Saccharomyces strains (Benito et al., 2014b; Domizio et al., 2017; Benito, 2019), the Sc. pombe treatments (SP) in this study produced the lowest final concentrations of glycerol. The high strain variability of this parameter (up to 20\%) in Sc. pombe and S. cerevisiae (Benito et al., 2014a, 2016b) explains this observation.

\section{L-lactic acid}

The final concentrations of lactic acid varied from 0 to $3.37 \mathrm{~g} / \mathrm{L}$, depending on the microorganisms involved in the fermentation (Table 1). The LT ..SP treatment showed the highest concentration of lactic acid, the levels of which were even higher than the lactic acid levels reported in the treatments that underwent MLF by LAB. The ability of L. thermotolerans to generate lactic acid from substrates other than malic acid explains this result (Kapsopoulou et al., 2005; Hranilovic et al., 2017, 2018; Benito, 2018; Vilela, 2018; Porter et al., 2019b; Fairbairn et al., 2021; Hranilovic et al., 2021). Previous studies that combined L. thermotolerans and Sc. pombe reported final levels of L-lactic acid varying from 2.77 to $3.41 \mathrm{~g} / \mathrm{L}$ (Benito et al., 2015a, 2016a, 2017, 2019; Escott et al., 2018; Wang et al., 2019; Benito, 2020). A wider range in the final level of lactic acid, varying from 0.22 to $5.13 \mathrm{~g} / \mathrm{L}$, depending on the inoculation strategy and timing, is reported in the literature regarding mixed cultures of $L$. thermotolerans and S. cerevisiae (Kapsopoulou et al., 2007; Gobbi et al., 2013; Benito et al., 2015b). The inoculation time of $S$. cerevisiae affects the growth and survival of $L$. thermotolerans, and consequently the final amount of lactic acid in the wine (Kapsopoulou et al., 2007). The later the inoculation with $S$. cerevisiae, the higher the final L-lactic acid concentration. The final L-lactic acid levels of the SC...OE and SCXOE treatments did not differ statistically (Table 1).

\section{Malic acid and total acidity}

The malic acid levels varied from 0 to $4.63 \mathrm{~g} / \mathrm{L}$, depending on the microorganisms involved in the fermentations (Table 1). $S c$. pombe consumed all the malic acid in the $S P$ and $L T$...SP treatments. This result shows the ability of some $S c$. pombe strains to degrade up to $100 \%$ malic acid during alcoholic fermentation (Benito et al., 2014b, 2015a, 2016a; Domizio et al., 2017; Minnaar et al., 2017a). The SCXOE and SCxLB 


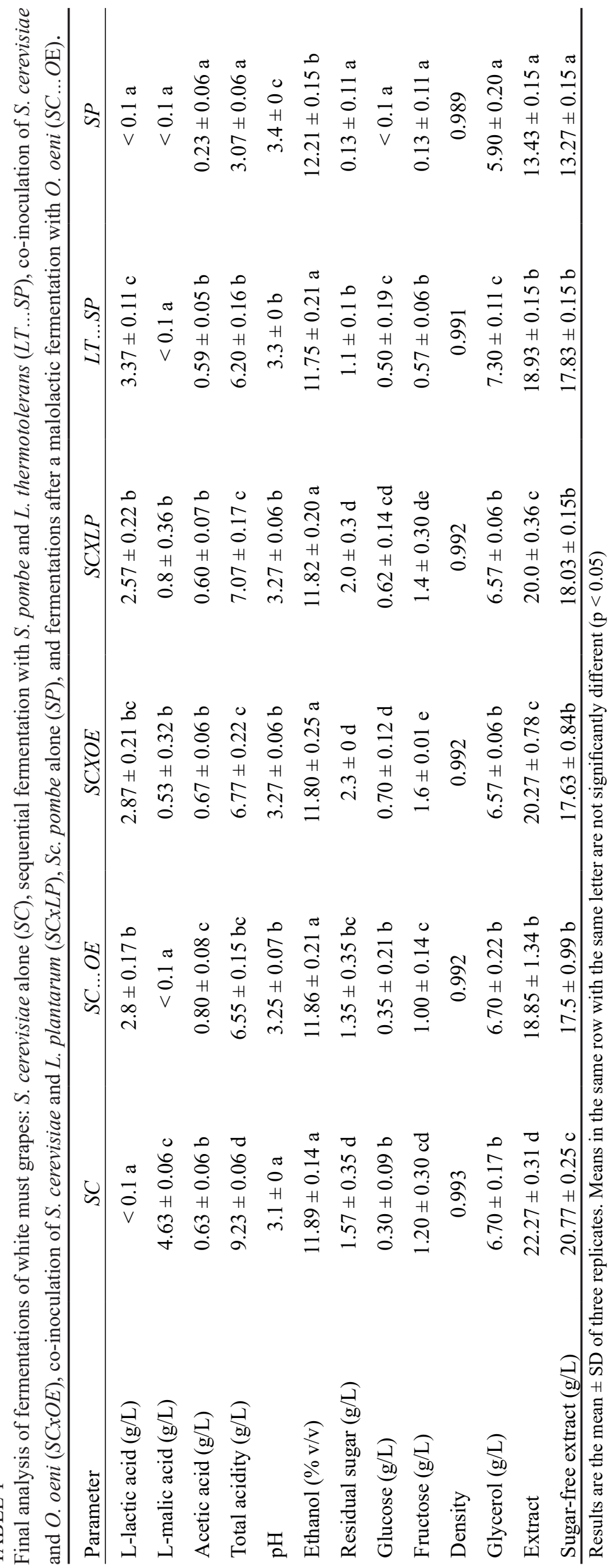




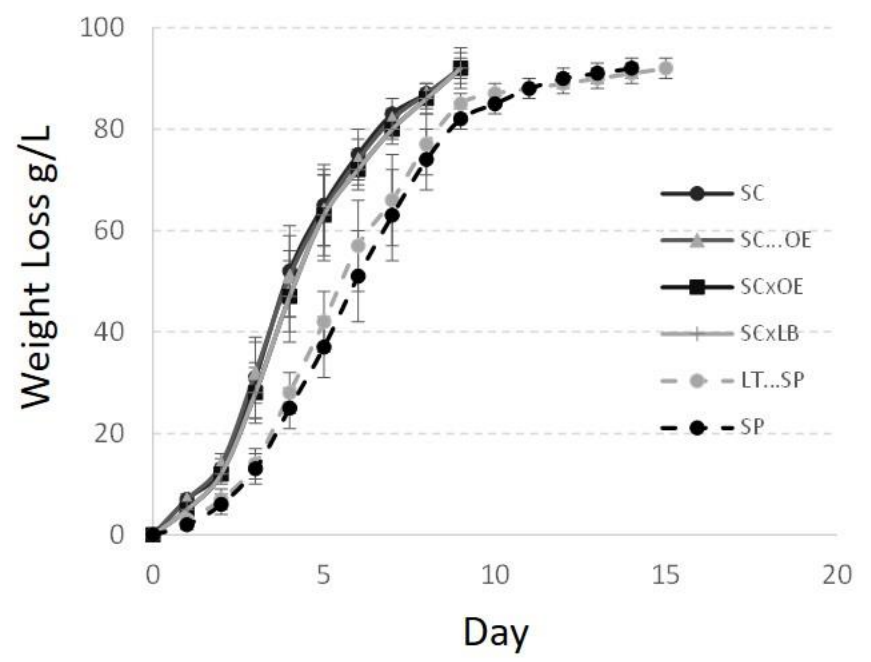

FIGURE 1

Fermentation kinetics of the different treatments measured gravimetrically by the total weight loss during the development of the alcoholic fermentation: $S$. cerevisiae alone $(S C)$, sequential fermentation with $S$. pombe and L. thermotolerans $(L T$...SP), co-inoculation of $S$. cerevisiae and $O$. oeni $(S C x O E)$, co-inoculation of $S$. cerevisiae and L. plantarum $(S C x L P)$, Sc. pombe alone $(S P)$, and fermentations after malolactic fermentation with $O$. oeni $(S C \ldots O E)$.

treatments consumed $88 \%$ and $82 \%$ of the initial malic acid, respectively. Previous studies reported deacidifications of approximately $89 \%$ for similar fermentation strategies involving L. plantarum, and from $77 \%$ to $90 \%$ for similar strategies involving $O$. oeni from must with initial contents of malic acid of approximately $2 \mathrm{~g} / \mathrm{L}$ (Minnaar et al., 2017b, 2019; Brizuela et al., 2018). It should also be considered that co-inoculations involving L. plantarum are thought to mainly consume malic acid in low acidic wines with a $\mathrm{pH}$ of over 3.5 (G-Alegría et al., 2004; Lucio et al., 2016, 2018). The original level of malic acid in the present study was $4.7 \mathrm{~g} / \mathrm{L}$ and the initial $\mathrm{pH}$ was 3.09. Other authors have reported important strain variability and $\mathrm{pH}$ influence in malic acid consumption that varies from $50 \%$ to $100 \%$ for L. plantarum in synthetic wine (Iorizzo et al., 2016).

Malic acid consumption influenced the final levels of total acidity in the resulting wines. The final total acidity levels varied from $3.07 \mathrm{~g} / \mathrm{L}$ to $9.23 \mathrm{~g} / \mathrm{L}$ (Table 1). Compared to the pure culture of $S$. cerevisiae $(S C)$, the pure culture of $S c$. pombe $(S P)$ reported a threefold decrease in the total acidity, while the malolactic fermentations performed by $O$. oeni and L. plantarum showed a one-fold decrease. The fact that $S c$. pombe metabolised all malic acid to ethanol and carbon dioxide by producing no lactic acid explains these enormous differences (Minnaar et al., 2017a; Benito, 2019).

\section{pH}

The reduction in malic acid affected the $\mathrm{pH}$ of the $S c$. pombe pure fermentation $(S P)$; the $\mathrm{pH}$ increased by 0.3 units compared to that of the $S$. cerevisiae pure alcoholic fermentation $(S C)$. Previous studies reported the potential of $L$. thermotolerans as a biological acidifier agent (Kapsopoulou et al., 2005, 2007; Balikci et al., 2016; Porter et al., 2019a). Although fermentations involving $L$. thermotolerans produced more lactic acid than the treatments involving LAB (Table 1), no significant differences were observed for $\mathrm{pH}$ because
Sc. pombe consumed the malic acid during the alcoholic fermentation.

\section{Acetic acid}

The acetic acid levels varied from 0.23 to $0.8 \mathrm{~g} / \mathrm{L}$ (Table 1). The levels detected with the sequential inoculation of L. thermotolerans and Sc. pombe ( $L T$...SP) did not differ significantly from the treatments fermented by $S$. cerevisiae. Although $S c$. pombe is historically known as a high producer of acetic acid, reaching levels of $1 \mathrm{~g} / \mathrm{L}$ (Benito et al., 2014b; Minnaar et al., 2017a; Miljić et al., 2017), recent studies have shown satisfactory results with regard to acetic acid levels. Some studies reported final acetic concentrations varying from $0.07 \mathrm{~g} / \mathrm{L}$ to $0.2 \mathrm{~g} / \mathrm{L}$ (Benito et al., 2016b; Du Plessis et al., 2017b; Scansani et al., 2020). The low acetic acid production by $S c$. pombe is related to strain selection processes (Benito et al., 2016b), combined fermentations with S. cerevisiae (Benito et al., 2014b; Benito, 2019) or fed-batch fermentation technology (Roca-Domènech et al., 2018). In this study, the selected Sc. pombe strain on its own $(S P)$ produced the lowest concentration of acetic acid, of $0.23 \mathrm{~g} / \mathrm{L}$ (Table 1). The $S C \ldots O E$ treatment showed the highest acetic acid concentration.

\section{Volatile compounds Higher alcohols}

In accordance with previous works (Benito et al., 2016a; Scansani et al., 2020), the Sc. pombe pure culture (SP) produced lower concentrations of most higher alcohols compared to the treatments involving $S$. cerevisiae or involving the sequential inoculation of $L$. thermotolerans and $S c$. pombe $(L T \ldots S P)$. The $S P$ fermentation produced approximately $30 \%, 50 \%$ and $50 \%$ less i-butanol, 3-methyl butanol and 2-phenyl ethanol, respectively than the fermentations involving $S$. cerevisiae (Table 2). Low levels of higher alcohols may increase the aromatic complexity. 


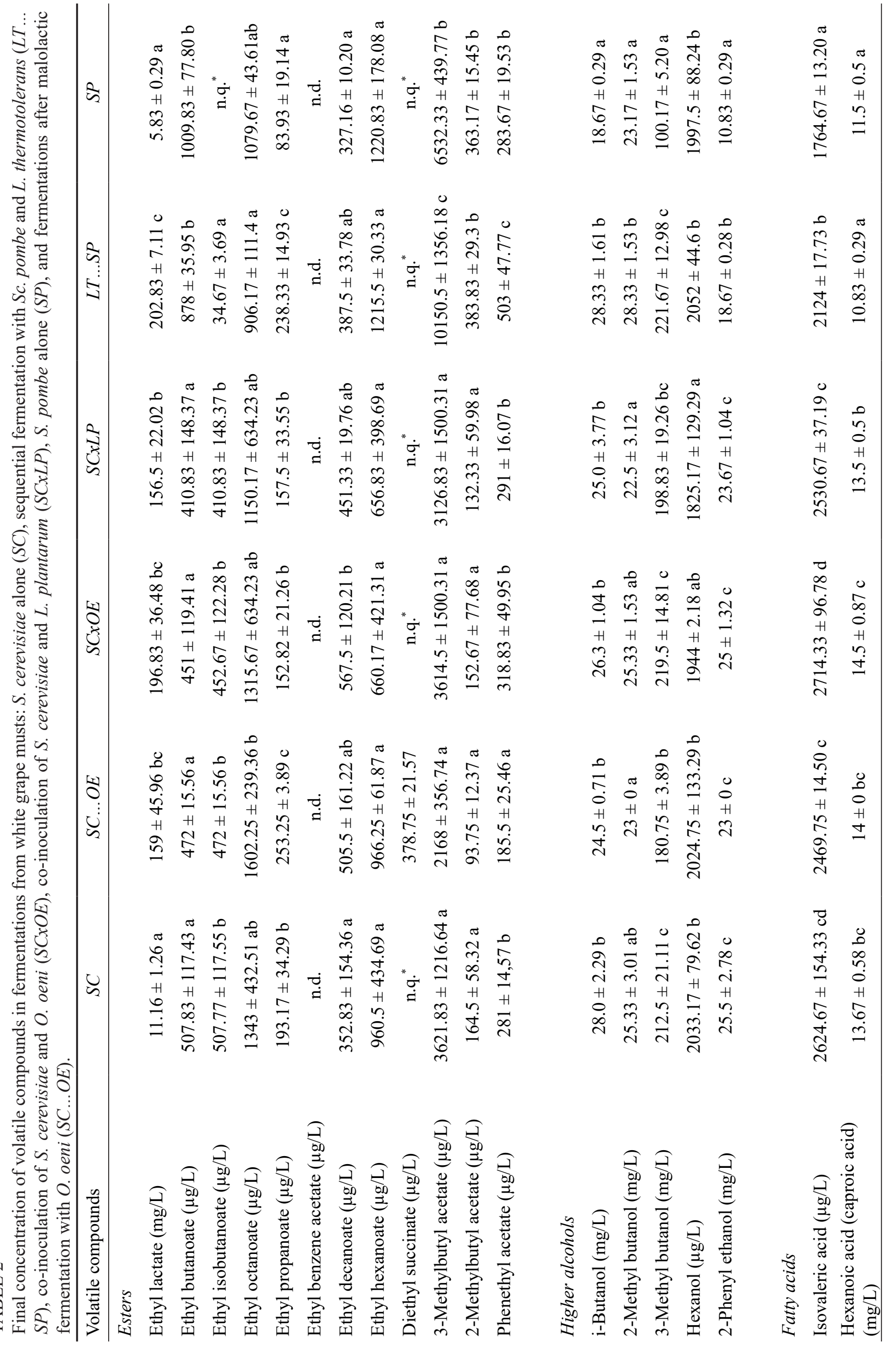




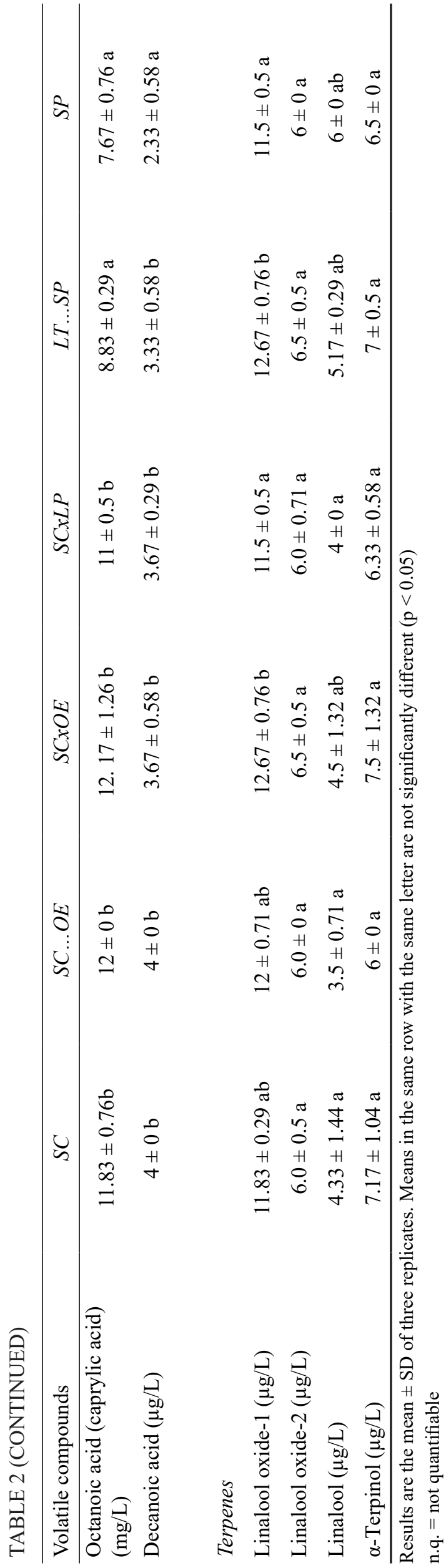

However, high concentrations mask the wine bouquet. The production of wine with a low concentration of higher alcohols allows the specific varietal aroma of grapes to be fully expressed (Ruiz et al., 2019).

As noted in other studies, mixed fermentations with L. thermotolerans and Sc. pombe (LT...SP) increase the concentration of all higher alcohols compared to the case with $S c$. pombe pure culture (SP) (Benito et al., 2016a). The ability of $L$. thermotolerans to increase the concentration of higher alcohols was observed in a previous study using mixed fermentation by $L$. thermotolerans and $S$. cerevisiae (Comitini et al., 2011). Subsequent studies using the same mixed culture showed increments in higher alcohol concentrations independent of the inoculation mode of coinoculation or sequential fermentation employed (Gobbi et al., 2013). Other authors have reported an increase in the levels of higher alcohol only in co-inoculation cultures (Balikci et al., 2016).

\section{Esters}

Esters can affect wine quality positively, imparting a fruity character to wine bouquets, especially wine from varieties with a neutral flavour (Ruiz et al., 2019). The concentration of ethyl lactate correlated with the lactic acid concentration (Table 2). Ethyl lactate traditionally appears during MLF because of an increase in lactic acid. The $\mathrm{pH}$ and ethanol concentration influence the production of ethyl lactate during MLF (Knoll et al., 2012). The lower the $\mathrm{pH}$ value and ethanol content, the higher the level of ethyl lactate. The $L T$...SP treatments showed the highest concentrations of ethyl lactate (Table 2) and lactic acid (Table 1). A previous study reported the weak ability of $L$. thermotolerans to produce esters, except for ethyl lactate (Gobbi et al., 2013).

A low production of ethyl isobutyrate (fruity, strawberry, lemon) (Sumby et al., 2010) was observed in the LT...SP treatments, whereas the concentration of this ester was not quantifiable in the $S P$ treatments. The ethyl propionate concentration was higher in the $L T \ldots S P$ and $S C \ldots O E$ treatments (Table 2), while the $S P$ treatments showed the lowest level of ethyl propionate. The $L T$...SP treatments reported the highest levels of 2-methylbutyl acetate and 3-methylbutyl acetate (isoamyl acetate), followed by the $S P$ treatments. The $L T$...SP treatments showed the highest concentrations of phenyl ethyl acetate, followed by the $S C x O E$ treatments. Other authors have reported $L$. thermotolerans as a high producer of phenyl ethyl acetate (Comitini et al., 2011; Gobbi et al., 2013; Benito, 2018; Porter et al., 2019b).

\section{Fatty acids}

Fatty acids have a low threshold level and therefore, depending on the concentration, can add complexity to or be detrimental to wine quality, imparting unpleasant characteristics such as rancid, cheesy, soy, pungent or fatlike (Ruiz et al., 2019). Both the LT...SP and SP treatments reported lower concentrations of all fatty acids compared to treatments involving $S$. cerevisiae. Regarding octanoic and decanoic acid, no significant differences were observed between the $S$. cerevisiae pure fermentation $(S C)$ and wine that underwent MLF (Table 2). 


\section{CONCLUSIONS}

This study shows interesting differences between the different biological deacidification strategies. The pure culture of Sc. pombe degraded all the malic acid and produced the lowest total acidity values. The results also showed that mixed cultures of $L$. thermotolerans and Sc. pombe can properly ferment musts that present adverse conditions for the correct performance of a classical malic acid fermentation. The Sc. pombe pure fermentation produced the lowest concentrations of acetic acid and higher alcohols, while yielding the highest ethanol production.

\section{LITERATURE CITED}

Balikci, E.K., Tanguler, H., Jolly, N.P. \& Erten, H., 2016. Influence of Lachancea thermotolerans on cv. Emir wine fermentation. Yeast 33(7), 313321

Bartowsky, E.J., Costello, P.J. \& Chambers, P.J., 2015. Emerging trends in the application of malolactic fermentation. Aust. J. Grape Wine Res. 21, 663-669.

Benito, Á., Calderón, F. \& Benito, S., 2016a. Combined use of S. pombe and L. thermotolerans in winemaking. Beneficial effects determined through the study of wines' analytical characteristics. Molecules 21(12), 1744

Benito, Á., Calderón, F. \& Benito, S., 2017. The combined use of Schizosaccharomyces pombe and Lachancea thermotolerans - effect on the anthocyanin wine composition. Molecules 22(5), 739.

Benito, Á., Calderón, F. \& Benito, S., 2019. Mixed alcoholic fermentation of Schizosaccharomyces pombe and Lachancea thermotolerans and its influence on mannose-containing polysaccharides wine composition. AMB Express 9(1), 17.

Benito, Á., Calderón, F., Palomero, F. \& Benito, S., 2015a. Combine use of selected Schizosaccharomyces pombe and Lachancea thermotolerans yeast strains as an alternative to the traditional malolactic fermentation in red wine production. Molecules 20(6), 9510-9523.

Benito, Á., Jeffares, D., Palomero, F., Calderón, F., Bai, F.-Y., Bähler, J. \& Benito, S., 2016b. Selected Schizosaccharomyces pombe strains have characteristics that are beneficial for winemaking. PLoS One 11(3), e0151102.

Benito, S., 2018. The impacts of Lachancea thermotolerans yeast strains on winemaking. Appl. Microbiol. Biotechnol. 102(16), 6775-6790.

Benito, S., 2019. The impacts of Schizosaccharomyces on winemaking. Appl. Microbiol. Biotechnol. 103(11), 4291-4312.

Benito, S., 2020. Combined use of Lachancea thermotolerans and Schizosaccharomyces pombe in winemaking: A review. Microorganisms 8, 655.

Benito, S., Hofmann, T., Laier, M., Lochbühler, B., Schüttler, A., Ebert, K., Fritsch, S., Röcker, J. \& Rauhut, D., 2015b. Effect on quality and composition of Riesling wines fermented by sequential inoculation with nonSaccharomyces and Saccharomyces cerevisiae. Eur. Food Res. Technol. 241(5), 707-717.

Benito, S., Palomero, F., Calderón, F., Palmero, D. \& Suárez-Lepe, J.A., 2014a. Selection of appropriate Schizosaccharomyces strains for winemaking. Food Microbiol. 42, 218-224.

Benito, S., Palomero, F., Gálvez, L., Morata, A., Calderón, F., Palmero, D. \& Suárez-Lepe, J.A., 2014b. Quality and composition of red wine fermented with Schizosaccharomyces pombe as sole fermentative yeast, and in mixed and sequential fermentations with Saccharomyces cerevisiae. Food Technol. Biotechnol. 52(3), 376.

Brizuela, N.S., Bravo-Ferrada, B.M., Pozo-Bayón, M.Á., Semorile, L. \& Tymczyszyn, E., 2018. Changes in the volatile profile of Pinot noir wines caused by Patagonian Lactobacillus plantarum and Oenococcus oeni strains. Food Res. Int. 106, 22-28.

Comitini, F., Gobbi, M., Domizio, P., Romani, C., Lencioni, L., Mannazzu, I. \& Ciani, M., 2011. Selected non-Saccharomyces wine yeasts in controlled multistarter fermentations with Saccharomyces cerevisiae. Food Microbiol. 28(5), 873-882.
Dicks, L.M.T. \& Endo, A., 2009. Taxonomic status of lactic acid bacteria in wine and key characteristics to differentiate species. S. Afr. J. Enol. Vitic. 30(1), 72-90.

Domizio, P., Lencioni, L., Calamai, L., Portaro, L. \& Bisson, L.F., 2018. Evaluation of the yeast Schizosaccharomyces japonicus for use in wine production. Am. J. Enol. Viticult. 69(3), 266-277.

Domizio, P., Liu, Y., Bisson, L.F. \& Barile, D., 2017. Cell wall polysaccharides released during the alcoholic fermentation by Schizosaccharomyces pombe and S. japonicus: Quantification and characterization. Food Microbiol. 61, 136-149.

Dukes, B. C. \& Butzke, C. E., 2013. Rapid determination of primary amino acids in grape juice using an o-phthaldialdehyde/ $\mathrm{N}$-acetyl-L-cysteine spectrophotometric assay. Am. J. Enol. Viticult. 49(2), 125-134.

Du Plessis, H., Du Toit, M., Nieuwoudt, H., Van der Rijst, M., Hoff, J. \& Jolly, N., 2019. Modulation of wine flavor using Hanseniaspora uvarum in combination with different Saccharomyces cerevisiae, lactic acid bacteria strains and malolactic fermentation strategies. Fermentation 5(3), 64.

Du Plessis, H., Du Toit, M., Nieuwoudt, H., Van der Rijst, M., Kidd, M. \& Jolly, N., 2017a. Effect of Saccharomyces, non-Saccharomyces yeasts and malolactic fermentation strategies on fermentation kinetics and flavor of Shiraz wines. Fermentation 3(4), 64

Du Plessis, H.W., Du Toit, M., Hoff, J.W., Hart, R.S., Ndimba, B.K. \& Jolly, N.P., 2017b. Characterisation of non-Saccharomyces yeasts using different methodologies and evaluation of their compatibility with malolactic fermentation. S. Afr. J. Enol. Vitic. 38(1), 46-63.

Du Toit, M., Engelbrecht, L., Lerm, E. \& Krieger-Weber, S. 2011. Lactobacillus: The next generation of malolactic fermentation starter cultures - An overview. Food Bioprocess Technol. 4, 876-906.

Dutraive, O., Benito, S., Fritsch, S., Beisert, B., Patz, C.-D. \& Rauhut, D., 2019. Effect of sequential inoculation with non-Saccharomyces and Saccharomyces yeasts on Riesling wine chemical composition. Fermentation 5(3), 79-95.

Escott, C., Morata, A., Ricardo-da-Silva, J.M., Callejo, M.J., González, M.D.C. \& Suarez-Lepe, J.A., 2018. Effect of Lachancea thermotolerans on the formation of polymeric pigments during sequential fermentation with Schizosaccharomyces pombe and Saccharomyces cerevisiae. Molecules 23(9), 2353

Fairbairn, S., Engelbrecht, L., Setati, M.E., Du Toit, M., Bauer, F.F., Divol, B. \& Rossouw, D., 2021. Combinatorial analysis of population dynamics, metabolite levels and malolactic fermentation in Saccharomyces cerevisiae/Lachancea thermotolerans mixed fermentations. Food Microbiol. 96, 103712.

Friedel, M., Patz, C.-D. \& Dietrich, H., 2013. Comparison of different measurement techniques and variable selection methods for FT-MIR in wine analysis. Food Chem. 141(4), 4200-4207.

G-Alegría, E., López, I., Ruiz, J.I., Sáenz, J., Fernández, E., Zarazaga, M., Dizy, M., Torres, C. \& Ruiz-Larrea, F., 2004. High tolerance of wild Lactobacillus plantarum and Oenococcus oeni strains to lyophilisation and stress environmental conditions of acid $\mathrm{pH}$ and ethanol. FEMS Microbiol. Lett. 230(1), 53-61.

Gobbi, M., Comitini, F., Domizio, P., Romani, C., Lencioni, L., Mannazzu, I. \& Ciani, M., 2013. Lachancea thermotolerans and Saccharomyces cerevisiae in simultaneous and sequential co-fermentation: A strategy to enhance acidity and improve the overall quality of wine. Food Microbiol. 33(2), 271281 .

Hranilovic, A., Bely, M., Masneuf-Pomarede, I., Jiranek, V. \& Albertin, W., 2017. The evolution of Lachancea thermotolerans is driven by geographical determination, anthropisation and flux between different ecosystems. PLoS One 12(9), e0184652.

Hranilovic, A., Gambetta, J.M., Schmidtke, L., Boss, P.K., Grbin, P.R., Masneuf-Pomarede, I., Bely, M., Albertin, W. \& Jiranek, V., 2018. Oenological traits of Lachancea thermotolerans show signs of domestication and allopatric differentiation. Sci. Rep. 8(1), 14812.

Hranilovic, A., Albertin, W., Capone, D.L., Gallo, A., Grbin, P.R., Danner, L., Bastain, S., Masneuf-Pomarede, I., Coulon, J., Bely, M. \& Jiranek, V., 2021. Impact of Lachancea thermotolerans on chemical composition and sensory profiles of Merlot wines. Food Chem. 349, 129015. 
Iorizzo, M., Testa, B., Lombardi, S.J., García-Ruiz, A., Muñoz-González, C., Bartolomé, B. \& Moreno-Arribas, M.V., 2016. Selection and technological potential of Lactobacillus plantarum bacteria suitable for wine malolactic fermentation and grape aroma release. LWT 73, 557-566.

Jolly, N.P., Varela, C. \& Pretorius, I.S., 2014. Not your ordinary yeast: NonSaccharomyces yeasts in wine production uncovered. FEMS Yeast Res. 14(2), 215-237.

Kanter, J.-P., Benito, S., Brezina, S., Beisert, B., Fritsch, S., Patz, C.-D. \& Rauhut, D., 2020. The impact of hybrid yeasts on the aroma profile of cool climate Riesling wines. Food Chem. 5, 100072.

Kapsopoulou, K., Kapaklis, A. \& Spyropoulos, H., 2005. Growth and fermentation characteristics of a strain of the wine yeast Kluyveromyces thermotolerans isolated in Greece. World J. Microbiol. Biotechnol. 21(8-9), 1599-1602.

Kapsopoulou, K., Mourtzini, A., Anthoulas, M. \& Nerantzis, E., 2007. Biological acidification during grape must fermentation using mixed cultures of Kluyveromyces thermotolerans and Saccharomyces cerevisiae. World J. Microbiol. Biotechnol. 23(5), 735-739.

Knoll, C., Fritsch, S., Schnell, S., Grossmann, M., Krieger-Weber, S., Du Toit, M. \& Rauhut, D., 2012. Impact of different malolactic fermentation inoculation scenarios on Riesling wine aroma. World J. Microbiol. Biotechnol. 28(3), 1143-1153.

Knoll, C., Fritsch, S., Schnell, S., Grossmann, M., Rauhut, D. \& Du Toit M., 2011. Influence of $\mathrm{pH}$ and ethanol on malolactic fermentation and volatile aroma compound composition in white wines. LWT-Food Sci. Technol. 44(10), 2077-2086

Lucio, O., Pardo, I., Heras, J.M., Krieger, S. \& Ferrer, S., 2018. Influence of yeast strains on managing wine acidity using Lactobacillus plantarum. Food Control 92, 471-478.

Lucio, O., Pardo, I., Krieger-Weber, S., Heras, J.M. \& Ferrer, S., 2016. Selection of Lactobacillus strains to induce biological acidification in low acidity wines. LWT 73, 334-341.

Miljić, U., Puškaš, V., Vučurović, V. \& Muzalevski, A., 2017. Fermentation characteristics and aromatic profile of plum wines produced with indigenous microbiota and pure cultures of selected yeast. J. Food Sci. 82(6), 1443-1450.

Minnaar, P.P., Du Plessis, H.W., Jolly, N.P., Van der Rijst, M. \& Du Toit, M., 2019. Non-Saccharomyces yeast and lactic acid bacteria in co-inoculated fermentations with two Saccharomyces cerevisiae yeast strains: A strategy to improve the phenolic content of Syrah wine. Food Chem. X 4, 100070.

Minnaar, P.P., Du Plessis, H.W., Paulsen, V., Ntushelo, N., Jolly, N.P. \& Du Toit, M., 2017b. Saccharomyces cerevisiae, non-Saccharomyces yeasts and lactic acid bacteria in sequential fermentations: Effect on phenolics and sensory attributes of South African Syrah wines. S. Afr. J. Enol. Vitic. 38(2), 237-244.

Minnaar, P.P., Jolly, N.P., Paulsen, V., Du Plessis, H.W. \& Van Der Rijst, M., 2017a. Schizosaccharomyces pombe and Saccharomyces cerevisiae yeasts in sequential fermentations: Effect on phenolic acids of fermented Kei-apple (Dovyalis caffra L.) juice. Int. J. Food Microbiol. 257, 232-237.

Olguin, N.T., Delfederico, L. \& Semorile, L., 2020. Colour evaluation of Pinot noir and Merlot wines after malolactic fermentation carried out by Oenococcus oeni and Lactobacillus plantarum Patagonian native strains. S. Afr. J. Enol. Vitic. 41(2), 210-217.
Patz, C.D., Blieke, A., Ristow, R. \& Dietrich, H., 2004. Application of FTMIR spectrometry in wine analysis. Anal. Chim. Acta 513(1), 81-89.

Porter, T.J., Divol, B. \& Setati, M.E., 2019a. Investigating the biochemical and fermentation attributes of Lachancea species and strains: Deciphering the potential contribution to wine chemical composition. Int. J. Food Microbiol. 290, 273-287.

Porter, T.J., Divol, B. \& Setati, M.E., 2019b. Lachancea yeast species: Origin, biochemical characteristics and oenological significance. Food Res. Int. $119,378-389$.

Rapp, A., Yavas, I. \& Hastrich, H., 1994. Einfache und schnelle anreicherung ("kaltronmethode") von aromastoffen des weines und deren quantitative bestimmung mittels kapillargaschromatographie. Deut. Lebensm.-Rundsch. 90, 171-174.

Roca-Domènech, G., Cordero-Otero, R., Rozès, N., Cléroux, M., Pernet, A. \& Mira de Orduña, R., 2018. Metabolism of Schizosaccharomyces pombe under reduced osmotic stress conditions afforded by fed-batch alcoholic fermentation of white grape must. Food Res. Int. 113, 401-406.

Roudil, L., Russo, P., Berbegal, C., Albertin, W., Spano, G. \& Capozzi, V., 2019. Non-Saccharomyces commercial starter cultures: Scientific trends, recent patents and innovation in the wine sector. Recent Pat. Food Nutr. Agric. 10, 1-13

Ruiz, J., Kiene, F., Belda, I., Fracassetti, D., Marquina, D., Navascués, E. Calderón, F., Benito, A., Rauhut, D., Santos, A. \& Benito, S., 2019. Effects on varietal aromas during wine making: A review of the impact of varietal aromas on the flavor of wine. Appl. Microbiol. Biotechnol. 103(18), 74257450

Scansani, S., Rauhut, D., Brezina, S., Semmler, H. \& Benito, S., 2020. The impact of chitosan on the chemical composition of wines fermented with Schizosaccharomyces pombe and Saccharomyces cerevisiae. Foods 9(10), 1423

Smit, A.Y. \& Du Toit, M., 2013. Evaluating the influence of malolactic fermentation inoculation practices and ageing on lees on biogenic amine production in wine. Food Bioproc. Technol. 6(1), 198-206.

Sumby, K.M., Bartle, L., Grbin, P.R. \& Jiranek, V., 2019. Measures to improve wine malolactic fermentation. Appl. Microbiol. Biotechnol. 103(5), 2033-2051

Sumby, K.M., Grbin, P.R \& Jiranek, V., 2010. Microbial modulation of aromatic esters in wine: Current knowledge and future prospects. Food Chem. 121(1), 1-16.

Sumby, K.M., Grbin, P.R. \& Jiranek, V., 2014. Implications of new research and technologies for malolactic fermentation in wine. Appl. Microbiol. Biotechnol. 98(19), 8111-8132.

Vilela, A., 2018. Lachancea thermotolerans, the non-Saccharomyces yeast that reduces the volatile acidity of wines. Fermentation 4(3), 56-61.

Vilela, A., 2019. Use of nonconventional yeasts for modulating wine acidity. Fermentation 5(1), 27-42.

Volschenk, H., Van Vuuren, H.J.J. \& Viljoen-Bloom, M., 2006. Malic acid in wine: Origin, function and metabolism during vinification. S. Afr. J. Enol Vitic. 27(2), 123-136

Wang, Y., Sheng, W., Li, M., Mi, L., Jiang, Y. \& Wang, J., 2019. Effect of sequential fermentation with Lachancea thermotolerans and Schizosaccharomyces pombe on the quality of Merlot dry red wine. Food Sci. 40(8), 102-111. 